\title{
Q ensino de Geografia em uma escola do campo e uma escola da cidade no mu- nicípio de Agudo-RS: características e diversidades
}

\section{The Geagraphy teaching on school field and a city school in the municipality of Agudo-RS: features and diversity}

Gerson Jonas Schirmer* Eduardo Schiavone Cardoso ** Marisa Dal' Ongaro***

\section{Resumo:}

A localização geográfica da escola, pode assumir um papel de destaque na formação escolar, sendo esta muitas vezes o elo entre o que o aluno vivencia no seu cotidiano e o que este aprende dentro da sala de aula. O presente estudo tem como objetivo apresentar uma análise do ensino de geografia em uma escola do campo e em uma escola da cidade no município de Agudo, localizado na Região Central do estado do Rio Grande do Sul. Para tanto, fez-se uma breve caracterização geral da rede de ensino do Município, pesquisou-se as características específicas de uma escola do campo e de uma escola da cidade, bem como a sua contribuição na compreensão e valorização do lugar. Constatou-se que apesar dos esforços por parte de alguns professores, embasado nos procedimentos adotados, a escola segue formando sujeitos sociais que não estabelecem uma verdadeira identidade com o lugar.

\begin{abstract}
:
The geographical location of the school, can play a key role in school education, which is often the link between what the student experiences in their daily lives and what it learns in the classroom. This study aims to present a geography teaching analysis at a field school and a city school in Agudo County, located in the Central Region of the Rio Grande do Sul state. Therefore, there was a brief characterization general education network of the City, looked up the specific characteristics of a field school and a school in the city, as well as its contribution to the understanding and appreciation of the place. It was found that despite efforts by some teachers, based on the procedures adopted, the school follows forming social subjects that do not establish a real identity with the place.
\end{abstract}

* Professor Doutor da Universidade Federal de Santa Maria, Campus de Cachoeira do Sul

** Professor Doutor do Departamento de Geociências da Universidade Federal de Santa Maria

*** Mestranda em Geografia na Universidade Federal de Santa Maria

Palavras-chave:

Agudo,

Ensino de Geografia,

Escola do campo,

Escola da cidade

Key-Words:

Agudo,

Teaching Geography

Countryside school,

City school 


\section{INTRODUÇÃO}

$\mathrm{O}$ município de Agudo, através das "escolas núcleo", tem concentrado um número maior de alunos em determinadas escolas do município. Com isso, busca-se diminuir as diferenças nas práticas de ensino das escolas do meio rural e das escolas do meio urbano com mais acesso a informações, acesso a internet, maior socialização entre os alunos de diferentes áreas. No entanto, de acordo com Schirmer (2013), os alunos da escola do campo, podem com isto estar sendo afastados de seu cotidiano, ou seja, tem-se uma "urbanização" do ensino e diminuição do elo existente entre o aluno e o ambiente onde vive, o campo, diminuindo também sua relação com o lugar.

Há ainda uma necessidade de se avaliar as vantagens e desvantagens existentes na prática de ensinoaprendizagem, em virtude da localização geográfica das escolas, bem como verificar a importância do ensino de geografia na valorização do lugar. Conhecer o lugar em que a escola esta inserida é indispensável ao professor, para que este possa realizar suas atividades educacionais voltadas à realidade do aluno, desta forma poderá perceber o seu significado, o valor da história e a cultura deste lugar. É a partir do lugar que nos identificamos no espaço e no mundo. Neste sentido, é essencial que o educador e o educando compreendam a realidade no qual se vive, para que haja uma atuação futura do educando, como agente transformador de seu meio.

Desta forma, a presente investigação pretende subsidiar a produção de informações, que beneficiarão o ensino-aprendizagem nas escolas do município de Agudo, valorizando e compreendendo a realidade local de cada aluno dentro do ambiente escolar.

Cabe ressaltar que para o desenvolvimento deste trabalho, foi escolhida uma escola do campo e uma da cidade para obtenção de dados mais aprofundados e para caracterizar o ensino geografia de cada uma dessas realidades.

\section{PROCEDIMENTOS METODOLÓGICOS}

Este estudo foi realizado através de uma abordagem qualitativa, que busca a compreensão detalhada dos significados e características da educação na escola do campo e da cidade na rede de ensino do município de Agudo - RS. Assim, busca-se através desta pesquisa a realização de uma análise destes dois espaços de ensino. Para tanto foi necessário observar as características das duas realidades do ensino de geografia. Essas observações foram realizadas durante três meses, durante o estágio obrigatório do curso de licenciatura em geografia, realizado durante os meses de outubro, novembro e dezembro do ano de 2013. Esta pesquisa classifica-se como descritiva-exploratória com abordagem qualitativa. Para se atingir os objetivos, foi necessário observar in loco as características da realidade da área de estudo De acordo com Sidnei (2006), a observação de campo é mais que uma etapa preparatória e constitui uma forma de apreensão da realidade.

Para o desenvolvimento do trabalho foram escolhidas as escolas: Escola Estadual de Educação Básica Professor Willy Roos e a Escola Municipal de Ensino Fundamental Três de Maio. A primeira escola foi escolhida por localizar-se na cidade e possuir alunos que vêm da zona rural estudando junto com alunos que são da cidade em uma mesma turma, o que resulta em turmas heterogêneas em relação à origem dos alunos, além das diferenças normalmente existente nas turmas.

Já a segunda escola, foi escolhida por localizarse na zona rural com alunos de características semelhantes, todos da zona rural, resultando em turmas mais homogêneas. Além disso, é uma das escolas da zona rural mais próxima para desenvolver o trabalho, o que reduziu os custos e o tempo de deslocamento. $\mathrm{Na}$ escola Willy Roos a série trabalhada foi o segundo ano do ensino médio. Já no caso da escola Três de Maio foi escolhida a turma do $9^{\circ}$ ano, por ser uma turma que logo terá de deixar de estudar em uma escola do meio rural, para estudar em uma escola da cidade no ensino médio.

Para aplicação de entrevistas, entrou-se em contato com as escolas de interesse para entrevistar os professores, os alunos e observar as aulas e o entorno da escola. Cabe ressaltar que os professores entrevistados foram apenas os que ministram aula para as turmas escolhidas para a pesquisa. Assim, foram entrevistados 8 professores da escola Três de Maio, de um total de 29 professores existentes na escola e 10 da escola Willy Roos, de um total de 44 professores. Os professores das demais disciplinas foram entrevistados para compreender dificuldades e facilidades encontradas de maneira geral nessas escolas, principalmente na capacidade de os professores relacionarem seus conteúdos com o 
lugar vivido dos alunos.

Nas entrevistas realizadas com os professores buscou-se abordar a origem destes, se são de origem urbana ou rural, se em suas aulas trazem atividades que envolvam o cotidiano dos alunos ou apenas utilizam livros didáticos. O contato com os professores foi realizado, com o intuito de melhorar relação em sala de aula entre educando e educador, investigando quais os temas que merecem mais destaque e qual a melhor forma de tratá-los, visando reforçar que professores busquem exemplos cotidianos com o intuito de melhor explicar os mais variados conteúdos de sala de aula.

\section{A REDE DE ENSINO DO MUNICÍPIO DE AGUDO}

A história da formação da rede de ensino no município de Agudo tem início com a chegada dos imigrantes alemães. Inicialmente, não havia recursos públicos. Porém, as comunidades organizavam-se em torno de um ideal maior, que era da Educação, porque já sabiam que educação era a maior herança que um pai podia passar para seu filho, ideal este trazido da Europa.

No entanto, tinha-se dificuldade para se ter escola e também professores. Nesse sentido, segundo relato de pessoas mais idosas, escolhia-se dentre as pessoas da comunidade aquele que possuía mais conhecimento para se tornar professor, sendo que as aulas eram dadas todas em dialeto alemão. Isto prevaleceu até a era Vargas, quando o dialeto alemão foi reprimido na região em virtude da segunda guerra mundial e da forte presença de integralistas dentre os imigrantes alemães. Já o local da escola normalmente era escolhido na casa do professor ou eram construídas com ajuda de toda comunidade interessada.

Com a institucionalização da maioria das escolas e com o apoio do governo do estado foram construídas diversas escolas entre a década de 60 e 70, as chamadas "brizoletas", escolas estas com pequeno número de alunos e de recursos, mesmo que localizadas sempre próximo aos locais com maior número de população no meio rural. Já a partir de 2000, tem-se a criação de escolas núcleos com maior número de alunos e recursos, onde os alunos, em grande maioria, são transportados para as escolas.

No inicio do ano letivo de 2014 o município de Agudo possuía 13 escolas entre municipais (08) estaduais (03) e particulares (02), atendendo cerca de 3.209 alunos (figura 1).

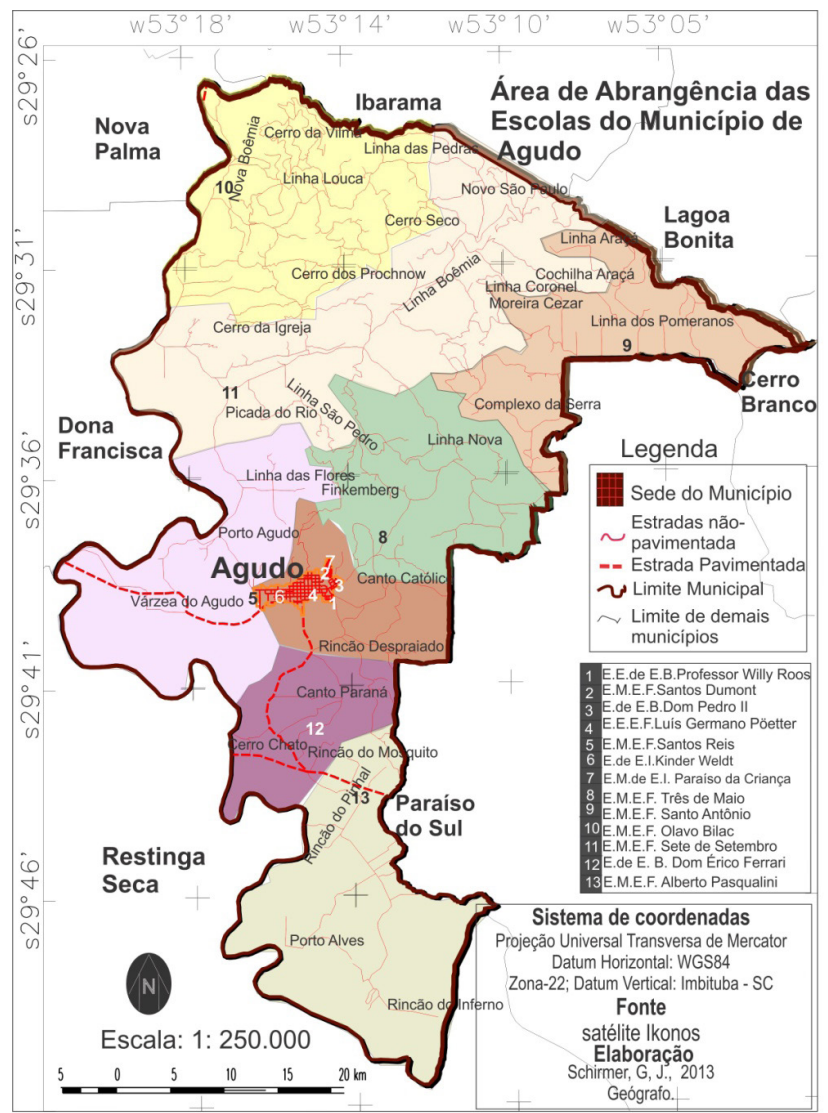

Figura 1: Mapa com localização e área de abrangência das escolas do município de Agudo

Fonte:SCHIRMER, 2013

Das 13 escolas, 6 delas estão localizadas no campo, sendo que apenas 1 destas 6, apresenta Ensino Médio para atender os alunos da zona rural, próximos de suas casas, a Escola de Educação Básica Dom Érico Ferrari. Nas demais localidades, os alunos devem se deslocar para a área urbana para cursar esse nível de ensino. Cabe destacar ainda que a Escola Municipal de Ensino Fundamental Santo Reis, localizada na área urbana, atende muitos alunos provindos da zona rural.

Dentre as demais escolas do meio urbano, a Escola Estadual de Educação Básica Willy Roos é a que mais atende alunos, tanto de origem rural quanto urbana, por ser esta a maior escola pública que disponibiliza o ensino médio no município. O número total de alunos das escolas municipais de Agudo, em 2014 é de 1.802 alunos. Deste total, 383 alunos estão na educação infantil, 1.419 estão no ensino fundamental. Nas escolas estaduais o número de alunos é de 1.279 em 2014. Destes 500 são do Ensino Fundamental, 583 são do Ensino Médio e 196 são de EJA. Já a escola particular 
atende 128 alunos, em todas as modalidades da Educação Básica.

Quanto ao transporte escolar da rede de ensino, a prefeitura é responsável por transportar os alunos residentes mais de $2 \mathrm{~km}$ da escola. Desta forma, 1.448 alunos possuem transporte gratuito na zona rural e 29 na área urbana. Cabe ressaltar que na área urbana há alunos que pagam o transporte escolar até as escolas. Para estes seria importante receber transporte público, mesmo distando menos de $2 \mathrm{~km}$, pois é perigoso eles andarem sozinhos pelas ruas e estradas, especialmente os que estão nos Anos Iniciais do Ensino Fundamental.

A área de abrangência das escolas pode ser definida a partir das linhas do transporte escolar gratuito. De um modo geral, limita-se de acordo com os pontos extremos de onde o transporte dos alunos de cada escola parte, buscando atender a um raio de distância que não aumente muito o tempo de trajeto dos alunos. Delimita-se assim de acordo com os caminhos que, além de acompanhar as localidades rurais do município, acompanha as porções do relevo que estão entre divisores de águas.

Esta delimitação não está relacionada com o número de alunos das escolas, pois as escolas localizadas na zona rural, que apresentam uma significativa área de abrangência, não apresentam obrigatoriamente o maior número de alunos. Do contrário, as escolas localizadas na área urbana apresentam a menor área de alcance, porém o maior número de alunos. O número de alunos está ligado principalmente à concentração populacional existente em determinada localidade. Já a área de abrangência da escola é determinada pela área espacial em que estão localizados seus alunos, bem como o grau de facilidade destes serem transportados para determinadas escolas.

Assim se os alunos de uma determinada escola forem filhos de agricultores de médias propriedades a escola poderá ter uma grande área de alcance, porém baixo número de alunos. Já, se dentro dessa área tiver predominância de pequenos agricultores, com varias pessoas compondo as famílias, a escola terá um elevado número de alunos, porém não necessariamente uma grande área de abrangência, gráfico 1.

$\mathrm{Na}$ localização da área de abrangência das escolas, observada na figura 1, destaca-se as diferentes localizações das escolas e seus alunos. Das escolas do campo, quatro estão ao norte da sede do município, onde o relevo apresenta declividades acentuadas, com propriedades agrícolas que produzem em sua grande maioria o fumo e duas escolas ao sul da sede do município, onde se tem predominantemente o cultivo do arroz. Sendo que a Escola Municipal de Ensino Fundamental Santos Reis, embora localizada na área urbana, também atende os alunos de porções produtoras de arroz.

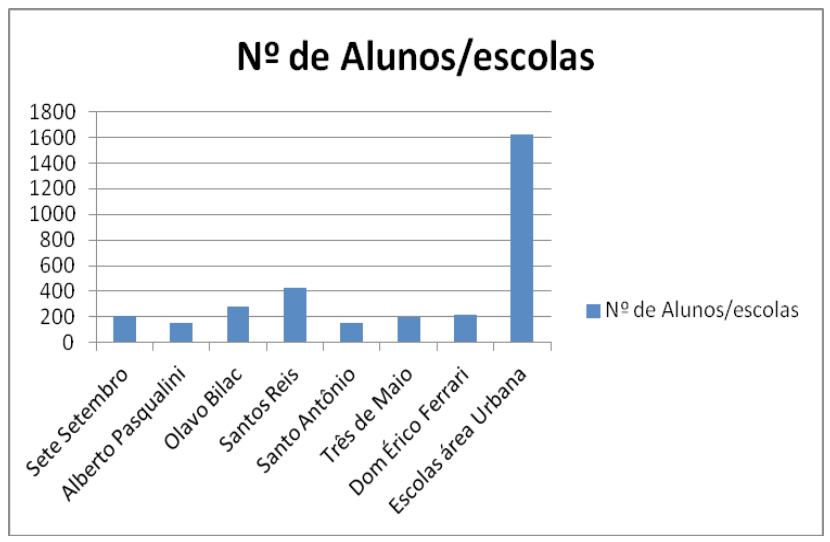

Gráfico 1: Quantidade de alunos por escola

De maneira geral, o município apresenta uma rede de Ensino Fundamental com escolas estratégicamente distribuídas no seu espaço, de modo a oportunizar a todas as crianças e adolescentes estudarem. Porém, no Ensino Médio há um distanciamento dos educandos da escola, na qual alunos que residem no extremo norte do município devem deslocar-se para a cidade para concluir Educação Básica. Este fato acaba por desestimular os jovens a continuar estudando após terminarem o ensino fundamental.

Os casos mais críticos são os da Escola Municipal de Ensino Fundamental Olavo Bilac e Escola Municipal de Ensino Fundamental Santo Antônio, localizadas nos extremos do município, que apresentam um significativo número de alunos, sendo que poucos seguem estudando no Ensino Médio. Isso ocorre devido a grande distância que tem de percorrer até a escola Estadual de Educação Básica Willy Roos, localizada na cidade. Esta distância, nos casos mais extremos, atingem em torno de $45 \mathrm{~km}$ da escola e faz com que os alunos tenham que acordar muito cedo e almoçar muito tarde.

Além desse fato, os estudantes não conseguem ajudar suas famílias, uma vez que com a idade 15 anos já estão inseridos nos trabalhos desenvolvidos na agricultura famíliar e assim acabam desistindo de estudar no ensino médio. Possivelmente se estas escolas localiza- 
das nos extremos do município tivessem ensino médio, o municipio teria maior número de alunos concluíndo este nível de ensino.

\section{A GEOGRAFIA “NA" REDE DE ENSINO DO MUNICÍPIO DE AGUDO}

O ensino de Geografia pode ser influenciado pela localização da escola, pois em alguns casos esta reflete a comunidade onde está inserida. Assim, estudar o contexto em que o aluno vive é imprescindível para que haja um bom aprendizado. No entanto, se faz necessário também este aluno conhecer outras realidades, sem ser afastado de seu espaço vivenciado.

Nidelcoff (1989), acrescenta que o papel do professor juntamente com seus educandos é de ver e compreender a realidade local para posteriormente poder expressar essa realidade, descobrindo-a e principalmente dando aos educandos os instrumentos necessários pra que possam analisar criticamente e promover ações sobre essa realidade a que estão condicionados.

$\mathrm{Na}$ busca de homogeneização da educação, na escola do campo, tem-se colocado o modo de vida urbano. Esta vem sendo aceita como o modelo padrão a ser vivido, no modo de falar, no modo de se vestir, no modo de consumir. Com isto, em alguns casos, pode-se perder valores e conhecimentos culturais locais, como por exemplo, traços linguísticos que identificam determinadas comunidades, conhecimentos de antepassados em relação a forma de lidar com a natureza formandose cidadãos completamente afastados do seu próprio cotidiano histórico. Conforme afirma Callai (2000):

O espaço construído resulta da história das pessoas, dos grupos que nele vivem, das formas como trabalham, como fazem/usufruem do lazer. Isto resgata a questão da identidade e a dimensão de pertencimento. É fundamental, neste processo, que se busque reconhecer os vínculos afetivos que ligam as pessoas aos lugares, às paisagens e tornam significativos o seu estudo (CALLAI, 2000, p.84).

Por outro lado, a escola urbana, muitas vezes não permite nem que $\mathrm{O}$ aluno saiba que existe a outra realidade, a do campo, sendo formados cidadãos completamente afastados da natureza, que veem uma floresta como algo sujo e desprezível ou intocada, veem o cidadão do campo como alguém alienado e ignorante, sem saber sequer a origem de seus próprios alimentos do dia-a-dia. Outro problema visível é o uso excessivo de internet, fazendo com que o jovem seja bastante in- fluenciado pelo mundo virtual e, ao se deparar com o fim da adolescência, pode vir a surgir problemas para aceitar trabalhos e relações concretas.

Nesse sentido, o educador possui um importante papel de mostrar as diversas realidades existentes e sempre remeter-se ao cotidiano real do lugar onde o aluno está inserido, daí a importância da Geografia na rede de ensino para explicar as diversidades espaciais existentes. De acordo com o caderno de Referências para uma Política Nacional de Educação do Campo, lançado em 2003 pelo Ministério da Educação:

[...] não é preciso destituir a cidade para o campo existir, nem vice-versa. O campo e a cidade são dois espaços que possuem lógicas e tempo próprio de produção cultural, ambos com seus valores. Não existe um espaço melhor ou pior, existem espaços diferentes que co-existem, pois muito do que é produzido na cidade está presente no campo e vice-versa (BRASIL, 2003, p.32).

O processo de aprendizagem, levando em consideração o estudo do lugar no ensino de Geografia, tem ganhado cada vez mais espaço nos últimos anos. Isso se deve à importância do estudo do lugar como um facilitador na compreensão do espaço geográfico. Porém, não basta somente conhecer o lugar enquanto questão epistemológica, se faz necessário entender as relações existentes nele, por exemplo, as relações sociais, histórico-culturais, econômicas e estas três com os aspectos naturais. Conforme expressa Libâneo (1990):

Os conteúdos da cultura, da ciência, da técnica, da arte e os modos de ação no mundo expressam os resultados da atividade prática dos homens nas suas relações com o ambiente natural e social. Nesse processo, os homens vão investigando o mundo da natureza e das relações sociais e elaborando conhecimentos e experiências, formando o que chamamos de saber cientifico. Nessas condições, o saber se torna objeto de conhecimento cuja apropriação pelas várias gerações, no ensino, constitui-se em base para a produção e a elaboração de novos saberes, (LIBÂNEO, 1990, p.129).

Conhecer o espaço onde a escola está inserida e fazer relações do conteúdo com este é o primeiro passo para que a aula flua com maior dinamicidade. Quando o professor conhece a realidade dos seus educandos consegue fazer relações dos conteúdos estudados com o cotidiano dos alunos tornando as aulas mais atraentes e valorizando o ensino de Geografia. Durante a pesquisa, percebeu-se, através de conversas informais, que os professores tem carência de informação sobre as características socioeconômicas e socioambientais do mu- 
nicípio de Agudo. Esta carência de informação dificulta o processo de ensino-aprendizagem, tanto nas aulas de Geografia quanto nas demais disciplinas.

Cabe ressaltar que o acesso às informações e às novas tecnologias é importante para todos, sendo papel do educador auxiliar os alunos a encontrar significado destas informações fazendo relações com seu cotidiano. Neste contexto Peres (2007), destaca a relevância de se explorar o cotidiano no ensino de Geografia apontando que:

A Geografia é um instrumento importante para a compreensão do mundo, portanto, pensar o ensino de geografia em sua função alfabetizadora é tomar as noções de espaço, território, lugar e ambiente como "conteúdos alfabetizadores". Nesta perspectiva o cotidiano se constitui no eixo articulador de uma prática alfabetizadora em que a aprendizagem da letra está intimamente vinculada à aprendizagem do espaço e as experiências culturais locais da criança (PERES, 2007, p. 36).

Torna-se mais fácil abordar a valorização do lugar quando a escola está mais próxima do cotidiano do educando. Porém, o processo de ensino-aprendizagem na disciplina de Geografia, por tratar dos fenômenos existentes no espaço, independe se a escola está localizada no campo ou na cidade, mas sim da homogeneização da turma em relação a sua vivência cotidiana e conhecimento do educador em relação aos educandos e a realidade do lugar. Há sim algumas facilidades de assimilação a determinados conteúdos que fazem relação com o lugar onde a escola está inserida.

\section{O ENSINO NA ESCOLA DO CAMPO}

O ambiente da escola do campo é um lugar onde deve-se valorizar os conhecimentos próprios da agricultura, além dos conteúdos de uma formação que integra a qualificação social e profissional, nesse sentido Caldart acredita que:

O aprendizado da paciência de semear e colher no tempo certo, o exercício da persistência diante dos entraves das intempéries e dos que se julgam senhores do tempo. Mas não fará isso apenas com discurso; terá que se desafiar e envolver os educandos e as educadoras em atividades diretamente ligadas a terra (CALDART, 2000, p. 29).

Sabe-se que há uma humanização através do trabalho e dessa forma ela invade também a escola. Essa humanização é aprimorada nas relações sociais, nos erros e no enfrentamento de dificuldades.
Deve-se construir uma formação que prepare as crianças para serem críticas, autônomas e também que respeitem as regras e direitos tanto dos colegas como das demais pessoas que as rodeiam, para isso é necessária uma construção de uma rotina. De acordo com Caldart:

Somos um ser de escolhas permanentes e delas depende o rumo de nossa vida e do processo histórico em que estamos inseridos. $\mathrm{E}$ as escolhas nem são apenas individuais nem podem ser apenas de um coletivo. Cada escolha é feita pela pessoa, movida por valores que são uma construção coletiva (CALDART, 2000, p. 32).

A tomada de escolhas é necessária, assumir a responsabilidade por elas passa a ser um desafio. É necessário trabalhar os valores humanos, pois eles possibilitam a coletividade e permitem que as pessoas tenham dignidade, porém esses valores precisam se transformar em ações.

Quando os educadores se assumem como trabalhadores do humano, formadores de sujeitos, muito mais que apenas professores de conteúdo de alguma disciplina, compreendem a importância de discutir sobre suas opções pedagógicas e sobre que ser humano estão ajudando a produzir e cultivar (CALDART, 2000, p. 28).

Contudo, não basta apenas trabalhar os valores culturais e humanos, é preciso que o educando busque conhecer a si mesmo e se desenvolver com sua identidade tornando possível uma realização pessoal. Para Vidor (2014), educar é alimentar para a vida, conduzir o ser humano para que ele possa se conduzir de forma adequada. Assim, ele acredita que é necessário conduzir para fora o valor intimo do educando e pedagogia para ele é: "A arte de ajudar a criança a desenvolver-se segundo o seu projeto de natureza, para construir o seu valor pessoal e contribuir na ordem do convívio social." De acordo com esses conceitos, a educação auxilia na construção de novos sujeitos sociais e conduz a formação humana.

A escola do campo é uma escola que esta inserida na realidade da comunidade a qual pertence, que fortalece o povo que é sujeito social, possuindo sua própria história, sua cultura, porém mobiliza uma atuação em prol da luta de um coletivo. Apesar disso Caldart afirma que:

...sair do campo para estudar, ou estudar para sair do campo não é uma realidade inevitável, assim como não são imutáveis as características marcadamente alheias à cultura do campo (CALDART, 2000, p. 29). 
Nesse sentido, a luta dos movimentos sociais passa a ser interesse de todas as pessoas menos favorecidas economicamente, uma vez que busca construir uma sociedade mais justa, onde se respeite os direitos e acredita que sempre que é possível mudar a realidade do povo. A respeito desses movimentos, no município de Agudo não há uma sede de MST, mas devido a presença da agricultura familiar tem-se o MPA (Movimento do Pequeno Agricultor). O MPA atua assessorando o agricultor nos financiamentos com menores taxas de juros para a compra de sementes, implementos agrícolas, entre outros. Este movimento luta também pela valorização no momento de venda dos produtos dos agricultores e incentiva a diversificação da propriedade para criar outras fontes de renda. Esses produtos como: mandioca, abóbora, batata, feijão não possuem conservantes e são destinados as escolas oferecendo uma alimentação de qualidade para os alunos do município.

Outro movimento que se destaca no município é o das trabalhadoras rurais que busca mais integração entre as mulheres, oferecendo festas nas escolas, cursos (artesanato, agroindústria), manifestações. Este é um movimento muito atuante dentro e fora das escolas, cuja principal característica é a luta e a organização dos grupos de trabalhadoras.

A organização também é um atributo indispensável para o bom andamento das aulas na escola do campo, para a conquista dessa organização tem-se a presença de regras de convivência associadas à rotina $\mathrm{e}$ levando em consideração o conhecimento que as crianças trazem para a sala de aula. Cabe ao professor estabelecer essa rotina em conjunto com a turma conforme as necessidades percebidas, atuando sobre os espaços e tempos e até mesmo recriando-a.

Para Benjamin (2001), a principal característica do ser humano, em oposição a todas as outras espécies, é exatamente a sua capacidade de imaginar o futuro e agir para construí-lo.

O meio em que a criança está inserida também interfere em sua personalidade, pois se os adultos são referência ao qual a criança imita a fala, eles também são de comportamento. Assim a criança além de imitar os adultos em casa ela também imita o professor dentro da sala de aula e nos demais ambientes, então o professor precisa ter cuidado em relação às regras construídas pelo grupo (turma e o professor) e suas demais atitudes.

Cabe aos professores, oportunizar às crianças atividades que as insiram em um contexto cultural, a fim de que conheçam diferenças e qualidades existentes nessas culturas, como é o caso da relação com as pessoas mais velhas, como vivem, no que acreditam, rotina, etc.

A capacidade especificamente humana para a linguagem habilita as crianças a providenciarem instrumentos auxiliares na solução de tarefas difíceis, a superarem a ação impulsiva, a planejarem a solução para um problema antes de sua execução e a controlarem seu próprio comportamento. Signos e palavras constituem para as crianças, primeiro e acima de tudo, um meio de contato social com outras pessoas. As funções comunicativas da linguagem tornam-se, então, a base de uma forma nova e superior de atividades nas crianças distinguindo-as dos animais (VYGOTSKY 1984, p.31).

Esse acesso ao conhecimento torna as crianças mais seguras e também mais criativas, pois elas acreditam em sua capacidade, por perceberem que podem ir além do que estava sendo realizado no cotidiano.

Na perspectiva construtivista de Piaget (1976), o começo do conhecimento é a ação do sujeito sobre o objeto, ou seja, o conhecimento humano se constrói na interação homem-meio, sujeito-objeto. Conhecer, consiste em operar sobre o real e transformá-lo à fim de compreendê-lo.

Tudo que as crianças aprendem elas atribuem um sentido, que é pessoal, uma vez que os interesses e o tempo de entendimento e apreciação se diferencia de uma criança para outra. Assim a experiência por si só não basta, é preciso que esta experiência seja significativa para elas e essa significação pode e deve acontecer através da ligação com a cultura e consequentemente com o conhecimento.

Nesse contexto, a função do professor e aluno estava associada a executar o processo concebido, planejado, coordenado e controlado por especialistas, supostamente habilitados - neutros, objetivos, imparciais. A organização do processo desejava garantir a eficiência, compensando e corrigindo as deficiências do professor e expandindo os efeitos de sua intervenção. Portanto, é o processo que define o que professores e alunos devem fazer (SAVIANI, 2000, p.13).

Considera-se assim que a criança está sempre aprendendo, mesmo sem perceber ela está permanentemente conhecendo coisas novas e reformulando conceitos prévios. Assim, o professor tem um papel importante na construção do conhecimento, ele não apenas deve apoiar as ideias e construções feitas pelas crianças, como também precisa estar sempre instigando e desafiando as crianças para que, de forma lúdica, possam ir além. 
Por fim, é preciso que o espaço da sala de aula esteja estruturado para promover a atividade a ser realizada. Do mesmo modo, o educador precisa compreender que a criança é capaz de aprender, e esta é a condição para uma prática pedagógica promotora do desenvolvimento.

É importante ressaltar que para Paulo Freire (1986), a aprendizagem precisa estar voltada para a realidade do aluno, precisa ter objetos que as crianças trabalham em seu cotidiano na comunidade. Nesse sentido, pode-se construir jogos e realizar brincadeiras, utilizando imagens, objetos traços da cultura local, que possibilitem a aprendizagens a partir de novas experiências aos alunos e amenizando dificuldades que no cotidiano são observadas. Assim a aprendizagem torna-se mais significativa, pois reflete a realidade vivenciada pelos alunos no campo. A partir de um trabalho que visa respeitar a individualidade de cada aluno tem-se como consequência um melhor resultado na construção do conhecimento.

Outro aspecto relevante é a indissociabilidade entre o cuidar e o educar visando o bem estar, o crescimento e o pleno desenvolvimento da criança. A formação continuada serve como "esteio", pois faz com que estejamos sempre buscando novo saberes, formas de aprendizagens e estratégias de ensino e ao mesmo tempo remodelando esse saber para que quando chegar ao aluno seja significante para ele.

Educar é, portanto, despertar. Se adotarmos esse ponto de vista, compreenderemos que a ação do despertar nunca é empreendimento prematuro, sendo indispensável entregar-se sistematicamente a ela desde os primeiros anos de vida, a fim de que a criança, mais tarde, possa compreendê-la como uma tendência natural de seu ser e dela faça uma faculdade permanente (Howard,1984).

Na educação, é necessário para uma boa atuação que conheçamos os nossos alunos, isso nos exige constantemente que repensemos nossa prática. Apenas de posse desse conhecimento é possível fazer uma reflexão sobre a realidade em que eles estão inseridos e planejar, atividades que os instiguem ao saber. O educador é um mediador, quem aponta o caminho, mas sem dar as respostas prontas, pois cabe ao aluno buscá-las e compreender o mundo que vive. De acordo com Contreras (2002), ao referir-se às praticas cotidianas, reconhece que muitas situações vividas na sala de aula envolvem ações realizadas espontaneamente, sem que haja momento de reflexão nesse processo.

\section{O ENSINO DE GEOGRAFIA NA ESCO- LA DO CAMPO: ESCOLA TRÊS DE MAIO}

A escola fundada em 1925, com o nome de Aula Três de Maio, era particular e mantida pelas famílias que colaboravam com o "Caixa Escolar". Este mantinha o salário da professora e custeava as demais despesas da Escola. Além do "Caixa Escolar", também eram feitas festas escolares, para angariar fundos para a manutenção do Educandário. Mais tarde a Escola passou a chamarse Escola Particular Três de Maio. Em 06 de março de 1972, pelo Decreto de Criação 251/78 e pela Lei Municipal $N^{\circ}$. 340, a Escola passou a ser Municipal e mantida pela Prefeitura Municipal com a denominação de Escola Municipal Três de Maio e, posteriormente Escola Municipal de $1^{\circ}$ Grau Incompleto Três de Maio.

Com o fechamento de escolas menores das localidades vizinhas, sentiu-se a necessidade da ampliação desta Escola. Com isso foi proposta pelo poder público do estado a nuclearização, que se realizou no ano de 2000 com a implantação gradativa das séries finais do Ensino Fundamental e também da Educação Infantil. Por isso o educandário passou a chamar-se Escola Municipal de Ensino Fundamental Três de Maio, (EMEF) (figura 2).

A partir de então a escola passou a atender os filhos de pequenos agricultores (fumicultores) da Linha Teotônia, Linha Branca, Linha Travessão, e Linha Nova. Os alunos da E. M. E. F. Três de Maio, caracterizam-se por apresentar diversidade no que se refere à etnia e credo. As diferenças socioeconômicas são menos acentuadas, caracterizando-se pela presença de crianças e adolescentes oriundos da classe média baixa e da zona rural na sua maioria. Cabe ressaltar que a predominância de pequenas propriedades neste local está ligada ao processo histórico de formação e ocupação do município e das características naturais, (Schirmer, 2010).

As crianças e os adolescentes apresentam relativa facilidade de integração ao ambiente da Escola. Isso deve-se principalmente por ser uma escola que não os desvincula de seu ambiente de vivência, uma vez que, além da escola estar no meio rural (figura 3), ela também apresenta áreas livres com gramados e horta escolar, o que reproduz o cotidiano do educandos. Assim, os alunos sentem-se fazendo parte deste ambiente. 
Como pode-se perceber na figura 3, a escola encontrase no meio rural. Assim, a visão, in loco, que os alunos tem da janela de sua escola são lavouras, principalmente de fumo e vegetação nativa, o que não os desvincula da realidade vivida em suas casas. Nesse sentido, a escola do campo traz uma maior proximidade do aluno com a natureza, mesmo que o aluno viesse da área urbana para estudar em uma escola do campo, desde criança teria este contato mais próximo dos diversos elementos naturais que são abordados no ensino de Geografia como: hidrografia, solo, vegetação, rochas, pois são mais visíveis na escola, facilitando a compreensão. Para os alunos não terem somente esta mesma visão do seu cotidiano, a escola dispõe de uma sala de informática com internet disponível para os alunos fazerem suas pesquisas e conhecer a realidade de outros espaços também.

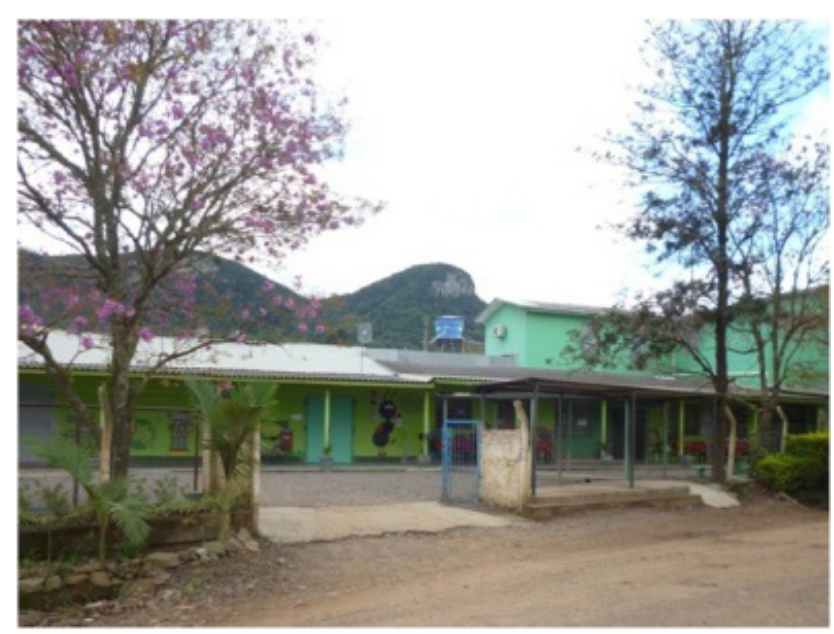

Figura 2: Escola Três de Maio, localizada em Linha Teotônia, Agudo-RS.

No entanto, há uma carência tanto de incentivo a pesquisa na internet, como, de mais tempo para os alunos fazerem uso deste meio para obter comunicação, informação e relacionar-se socialmente, pois a grande maioria dos alunos das escolas do campo não possui internet disponível em suas casas, sendo a escola o primeiro e único contato com esta tecnologia.

Assim, há pontos positivos de se ter estas escolas núcleo no campo para não desvincular os alunos de sua relação com a natureza e atividades cotidianas, porém falta o incentivo e acesso às novas tecnologias sob orientação de um docente para que a utilizem com o intuito de melhorar seu cotidiano. Além disso, teve-se uma significativa melhoria na infraestrutura das escolas do campo.

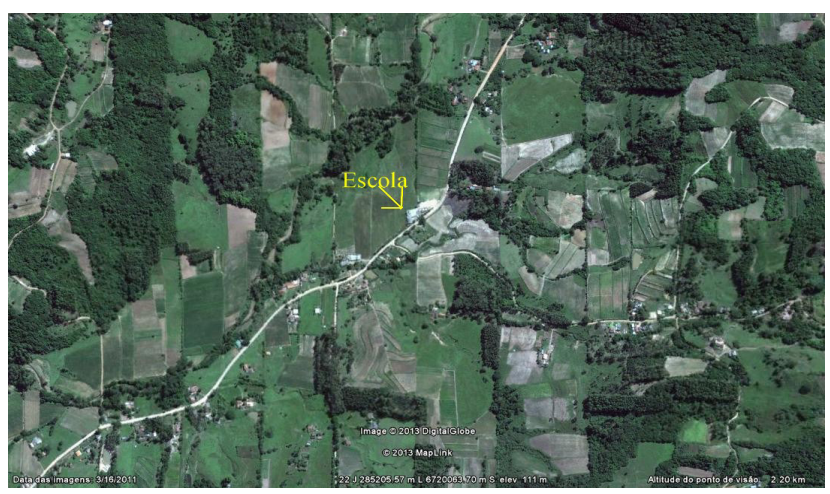

Figura 3: Localização da E. M.de E. F. Três de Maio, Linha Teotônia, Agudo-RS.

Fonte: Google Earth.

Sete professores, de um total de oito docentes que lecionam para o $9^{\circ}$ ano na escola Três de Maio, são oriundos da zona rural, porém alguns destes tem sua atual residência na área urbana. O que os levou a lecionar nessa escola, com exceção de uma professora, é o fator proximidade. Um dos professores de Geografia desta escola possui formação em História, o que dificulta trabalhar com os aspetos naturais como geologia, solo, clima, vegetação, hidrografia e relevo, na disciplina. Porém, esta não é uma realidade apenas desta escola.

Com a nova reforma curricular de ensino, que trabalha por área do conhecimento, professores de Sociologia, de História e de Geografia podem lecionar todas essas disciplinas, porém quando são abordados conteúdos específicos da ciência geográfica, os professores que não tem formação na disciplina sentem dificuldade, bem como estabelecer relações com o cotidiano dos alunos. Nesse sentido, o educador que faz parte ou conhece a realidade do educando auxilia e facilita estas relações.

Os professores entrevistados nesta escola consideram importante a localização da escola próximo das residências dos alunos no meio rural, pois torna o ambiente mais tranquilo, facilitando o processo de ensino aprendizagem. De acordo com Wizniewski (2010), o papel dos educadores do campo é de possibilitar dinâmicas pedagógicas que resgatem a cultura e o significado de se viver no campo com dignidade e de forma sustentável. Assim, a valorização do lugar e as questões ambientais são de grande relevância para ser trabalhadas nas aulas de geografia, buscando maior interação com os alunos.

Dos pais de 21 alunos do $9^{\circ}$ ano, 20 trabalham 
na lavoura com cultivo do fumo e apenas o pai de uma aluna é pedreiro. Dezessete dos 21 alunos ajudam seus pais nas atividades da lavoura desde cedo, iniciando com cerca de 11 ou 12 anos de idade. Os que ajudam a família disseram que normalmente ajudam com entusiasmo, pois há um incentivo para trabalharem, animados pela possibilidade de adquirir uma bicicleta, uma moto ou mesmo dinheiro ao final da safra.

Sabe-se que há algumas exceções no município onde os adolescentes são pressionados a trabalhar sem incentivo, porém isto tem diminuído significativamente nos últimos anos devido à legislação e fiscalização não permitir a presença de crianças e adolescentes na lavoura. Por outro lado, isto também tem provocado o "desenraizamento" do jovem com a lavoura, diminuindo o conhecimento sobre esta prática. Por vezes, também há um desapego dos adolescentes pelas atividades realizadas no campo, visando o trabalho na cidade como mais fácil e mais bem remunerado.

Já a prática de participar efetivamente nas atividades do campo junto com seus pais, divide a opinião dos alunos quanto ao gostar de ir para a escola e estudar. Isso se deve em grande maioria pela falta de relacionar os conteúdos escolares com o seu cotidiano, dando significado prático das matérias para as atividades realizadas em casa, tornando assim necessário estudar para viver no campo com maior conhecimento e maior qualidade de vida. Nesse sentido, percebe-se que os alunos nessa fase de ensino ficam em dúvida se o estudo contribui para a realização de suas atividades.

Alguns desses alunos já estão convencidos de que querem continuar no meio rural trabalhando na lavoura. Dos 21 alunos, 8 querem continuar, 9 não querem mais ficar neste ambiente, por ser uma vida muito difícil, onde sofrem com o calor do sol e trabalham no pesado e 4 disseram que tanto faz se for na cidade ou no campo para viver.

Quanto às questões ambientais, os alunos possuem consciência da importância de se ter uma relação harmônica com o meio ambiente, em unanimidade. Todos disseram que cuidam para não descartar o lixo no meio ambiente. Nesse sentido, eles procuram discutir a importância de cuidar do meio ambiente para ter uma melhor qualidade de vida, com ambiente mais limpo.

Quando se pergunta a opinião sobre a cidade, 19 dos 21 alunos gostam, por se ter acesso a mercadorias e maior relação com as pessoas. Porém acham as pes- soas que vivem na cidade muito "delicadas" e que seus trabalhos são muito mais "simples" de ser realizado, sem necessidade de se esforçar, braçalmente. Está intrínseco nesses jovens, que o trabalhar é o ato braçal e não o intelectual. Essa distinção é difícil de ser compreendida por eles, de que o trabalho intelectual realizado na cidade também é um trabalho e que é necessário para toda a sociedade.

\section{O ENSINO DE GEOGRAFIANA CIDADE: ESCOLA PROFESSOR WILLY ROOS}

O patrono da escola é o Professor Willy Roos, escolhido pela sua determinação e dedicação às causas educacionais e sociais do município de Agudo. Acompanhou a história deste educandário desde a sua fundação como Ginásio Estadual em 16/03/1962.

A partir de 1978 este ginásio passou a chamar-se Escola Estadual Duque de Caxias, e em 1979 foi criada a Escola Estadual de $2^{\circ}$ Grau de Agudo, ambas funcionando no mesmo prédio. Em 1982 a escola de $2^{\circ}$ grau recebeu o nome do Professor Willy Roos ( um ano após seu falecimento) e em 1989 as duas escolas foram unificadas sob a denominação de escola Estadual de $1^{\circ}$ e $2^{\circ}$ Graus Professor Willy Roos, sendo que a partir de 2000, esta passou a denominar-se Escola Estadual de Educação Básica Professor Willy Roos.

Nesta escola estudaram cidadãos e cidadãs que fizeram a continuam fazendo acontecer a realidade do município em todos os setores. É o propósito da escola: oferecer uma educação participativa e ensino de qualidade refletida na ação e comprometimento diário de seus docentes, funcionários e alunos desde a pré-escola ao $3^{\circ}$ ano do ensino médio.

A escola conta com 44 professores e 10 funcionários, sendo 7 professores contratados emergencialmente. Todos os funcionários são nomeados através de concurso público, estando 2 em estágio probatório. Quanto ao grau de escolaridade do corpo docente, apenas dois não possuem o curso de licenciatura plena concluído.

Embora haja um grande número de alunos provindos do meio rural a escola localiza-se na área urbana, localizada na rua Germano Hentscke, Bairro Centro da Cidade de Agudo (figura 4).

Dentre os professores que lecionam no Ensino Médio, foram entrevistados 10. Destes 8 são oriundos e vivem na área urbana, o que dificulta muitas vezes o en- 
tendimento do cotidiano dos educandos provindos do meio rural. Dentre os motivos que os levaram a lecionar nesta escola, o principal é a proximidade de suas moradias com a escola para 9 dos 10 professores. Apenas uma professora citou a oportunidade de trabalho, tendo em vista ser oriunda de outro município.

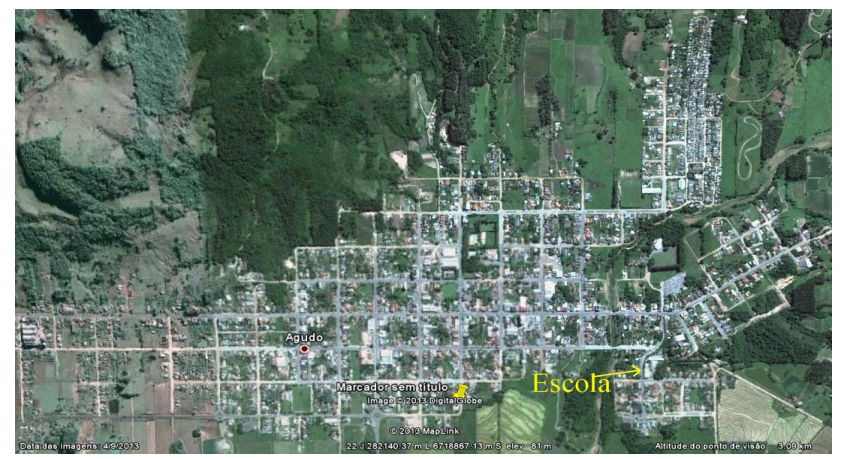

Figura 4: Localização da escola na área urbana de Agudo-RS. Fonte: Google Earth.

Percebe-se uma grande dificuldade de se trabalhar a valorização do lugar nas aulas de Geografia por parte dos professores, principalmente no Ensino Médio. Dentre os motivos citados estão: dificuldade de relacionar o cotidiano dos alunos com o conteúdo e a reforma do Ensino Médio que reduziu as aulas de geografia para apenas 45 minutos semanais.

Os professores acreditam que com a localização da escola mais próxima dos alunos, consegue-se melhor abordar os conteúdos relacionando com o cotidiano deles. Assim, a localização da escola pode influenciar no processo de ensino-aprendizagem, pois se a escola está localizada no meio rural será mais fácil abordar conteúdos sobre agricultura e sobre os aspectos físico-naturais, já se a escola está localizada na cidade torna-se mais fácil abordar as questões da globalização e as problemáticas sociais e econômicas.

Mesmo que o período das aulas de geografia no ensino médio tenha sido reduzido, a professora desta disciplina busca tratar as questões ambientais em suas aulas. Embora por vezes não conheça muito bem as diversas atividades realizadas pelos alunos, ela sempre localiza essas questões levando em consideração a realidade local. Já os professores das demais disciplinas muito pouco consideram as questões socioambientais.

Dentre as atividades realizadas pelos 23 alunos entrevistados e seus pais, a agricultura aparece como a principal. A grande maioria dos alunos é oriunda do meio rural, já que esta escola absorve os alunos da por- ção norte do município que seguem estudando para terminar o Ensino Médio. Estes normalmente ajudam seus pais na agricultura familiar. Dentre os alunos da cidade as atividades dos pais é o trabalho de empregado na fábrica de calçado Botero ou no comércio, com exceção dos pais de uma aluna que mora na Vila Caiçara, que trabalham nas lavouras de fumo próximas da cidade.

De um modo geral os alunos gostam de vir a esta escola, por ser não apenas um local de ensino, mas também de socialização, descontração e fuga da rotina cotidiana da lavoura. Os alunos que pretendem continuar estudando, são bem divididos, 10 do total de 23 pretendem fazer uma graduação. Os alunos que não querem continuar, dizem que não gostam de estudar. Os que moram na zona rural gostam de trabalhar na lavoura, sentem-se livres, além disso, argumentam não ter emprego para todos que fizerem graduação. Já os que querem continuar estudando, buscam uma vida mais fácil na cidade, com menos esforço braçal, sem exposição ao sol em dias quentes e salário garantido no final do mês. No entanto, todos concordam que a educação básica contribui para as suas atividades.

Todos os alunos da turma mostraram preocupação com as questões ambientais, tanto os que moram no meio rural, quanto os da área urbana, sendo que os da área urbana apresentam uma visão ambientalista mais radical, considerando muitas vezes a natureza intocável. Isso se deve, principalmente, por não entenderem muitas vezes a necessidade se utilizar a terra para cultivar, pois sem utilizá-la não se pode produzir o alimento consumido na cidade.

Quanto às atitudes para ter uma boa relação com o meio ambiente, 22 dos 23 alunos acreditam ser importante não jogar lixo em qualquer lugar. Uma única aluna destacou uma visão mais complexa da questão ambiental, como por exemplo, cuidar das áreas de preservação permanente que são importantes para manter o leito dos rios normal e evitar a erosão das encostas.

De um modo geral todos os alunos em questão possuem relação com alguém (parente ou amigo) do campo ou vivem na zona rural. Nesse sentido, eles sabem que são de grande importância as pessoas que vivem no campo, pois são elas que produzem os alimentos consumidos por todos. No entanto, há muitas vezes uma visão de ironia em relação à simplicidade das pessoas do campo. Percebeu-se isso em 3 alunos residentes na cidade que referiram-se ao modo de falar dos 
colegas, mais coloquial, titulando-os de "grosseiros". Embora essa visão venha sendo cada vez mais superada.

\section{CONSIDERAÇÕES FINAIS}

Durante a pequisa e a análise dos resultado percebeu-se que a valorização do lugar vai depender mais enfáticamente da vontade do professor em abordar ou não em sua aula a realidade vivida pelos educados. Assim, apesar do esforço por parte da grande maioria dos professores, percebeu-se que lhes falta maior conhecimento em relação ao lugar em que a escola está inserida, o cotidiano dos alunos e o contexto global do município. Isto resulta na formação de cidadãos com pouca identidade com o lugar onde vivem, pois conhecer a realidade do educando e relacionar os conteúdos de sala de aula com seu cotidiano é uma forma de trabalhar a valorização do lugar.

As vantagens e desvantagens encontradas quanto a localização da escola para o ensino aprendizagem de Geografia são diferentes, pois em uma escola do campo os alunos possuem maior facilidade no entendimento dos aspectos físico naturais, porém os aspectos Sócioeconômicos e da globalização os educandos das escolas da cidade apresentam maior facilidade de entender. Isto se dá, devido aos alunos da escola do campo, no turno inverso ao das aulas, estarem normalmente envolvidos com as atividades das lavouras junto com seus pais, já os alunos da cidade no turno inverso, normalmente, estão utlizando a internet e outros meios de comunicação que tragam informações sobre economia e aspectos sociais.

Ao se trabalhar com a escola do campo, percebeu-se que para ela formar cidadãos críticos e empenhados numa real transformação social, primeiramente, é preciso que ela valorize o espaço existente no seu entorno e, sobretudo, respeite os saberes acumulados historicamente pelos seus indivíduos. O espaço rural pode ser um aprendizado para se pensar e aderir a uma nova realidade educacional, buscando o desenvolvimento e o aperfeiçoamento das habilidades necessárias para a formação dos profissionais de educação, tornando os educadores e educandos capazes de reconhecer a realidade do "lugar" em que estão inseridas as escolas do campo.

Porém na escola da cidade tem-se a possibilidade de trabalhar as questões sociais vividas cotidianamente com maior disponibilidade e auxílio de tecnologias e di- namicidade. Para o educando da cidade torna-se mais difícil compreender as problemáticas ambientais como processos erosivos, por exemplo, que afetam os aspectos naturais, pois seu contato com a natureza é reduzido, onde muitas vezes não se considera parte desta. Esta realidade, nos últimos anos, tem atingido mesmo cidades pequenas como Agudo, visto que os adolescentes passam mais tempo conectados a alguma rede social, do que observando o que acontece para fora da janela de sua casa, no trajeto da escola ou em seu município. De certa forma possuem uma vida virtual, na qual só existe o que está presente na rede social.

No entanto, cabe ao educador fazer com que os educandos percebam as diferenças e semelhanças que existem entre a escola, o cotidiano e o lugar vivido, tanto nas questões socioeconômicas quanto socioambientais. Assim a escola não deve parar no tempo e sim atentar para as transformações e os desafios presentes, cumprindo o seu papel. Para isso os profissionais de educação devem constantemente estar preocupados e comprometidos em despertar nos discentes o entusiasmo pela busca do conhecimento.

\section{REFERÊNCIAS BIBLIOGRÁFICAS}

BENJAMIN,C.; CALDART, R. S.; Projeto Popular e Escolas do Campo. Brasília-DF: Articulação Nacional Por Uma Educação Básica do Campo, 2000. Coleção Por Uma Educação Básica do Campo, $2^{a}$ Edição: setembro 2001.

BRASIL. Ministério da Educação. Grupo Permanente de Trabalho de Educação do Campo. Referências para uma política nacional de educação do campo. Brasília, 2003. Disponível em: <http://www.ce.ufes. br/educacaodocampo/ down/cdrom1/pdf/007.pdf $>$ Acesso em: 03 de set. de 2013.

CALLAI, H. C. A Geografia no Ensino Médio. In: Terra Livre - As Transformações do Mundo da Educação - Geografia, Ensino e Responsabilidade Social. São Paulo: Associação dos Geógrafos Brasileiros, (14): p. 56-89, jan./jul. 1999.

CALDART, R. S. A escola do campo em movimento. In: BENJAMIN, C.; CALDART, R. S. Projeto popular e escolas do campo. Brasilia, DF, 2000. 
CONTRERAS, J. A autonomia de professores. São Paulo: Cortez, 2002. p. 296.

FREIRE, P. Educação como prática para a liberdade. Rio de Janeiro: Paz e Terra, 1986.

HOWARD, W. A Música e a Criança. São Paulo: Summus,1984.

Libâneo, L.C.; Democratização da escola Pública: a pedagogia histórico-crítico-social dos conteúdos. São Paulo:Loyola, 1990.

NIDELCOFF, M. T. A escola e a compreensão da realidade. São Paulo: Editora Brasiliense, 1989, 16 ed.

PERES, A. F. Saberes e identidade profissional em um curso de formação de professores de língua portuguesa. Londrina, 2007, 229. Tese (Doutorado em Estudos da Linguagem) Universidade Estadual de Londrina, Londrina, 2007.

PIAGET, J. Psicologia e pedagogia. Tradução Editora Forense Universitária - Dirceu Accioly Lindoso e Rosa Maria Ribeiro da Silva. Rio de Janeira: Forense Universitária, 1976.

SAVIANI, D. Escola e Democracia: teorias da educação, curvatura da vara, onze teses sobre educação e política. 33 . $^{a}$ ed. revisada. Campinas: Autores Associados, 2000.

SCHIRMER, G.J., Mapeamento Geoambiental Municipal de Agudo-RS. Monografia Geografia-Bacharelado_UFSM, Gerson Jonas Schirmer, 2010.

SCHIRMER, G.J., A valorização do lugar a partir do ensino de geografia na escola do campo e da cidade:o caso do município de Agudo-RS. Monografia Geografia-Licenciatura Plena_UFSM, Gerson Jonas Schirmer, 2013.

Wizniewski,C.F. A contribuição da Geografia na construção da educação do campo. Experiências e diálogos em educação do campo. Fortaleza:Edições UFC, 2010,129p.

VIDOR, A.; BARBIERI, J.; GIORDANI,E.M.; Uma nova pedagogia para a sociedade futura: princípios práticos. São João do Polêsine: Fundação Antonio
Meneghetti-Ontopsicologia Editora Universitária, 2014.

VYGOTSKY, L. S. Pensamento e Linguagem. Rio de Janeiro: Martins Fontes, 1998.

Correspondência dos autores:

Gerson Jonas Schirmer

e-mail: geogersonjs@gmail.com

Eduardo Schiavone Cardoso

e-mail: eduscard@ig.com.br

Marisa Dal'ongaro

e-mail: marisa.curso@hotmail.com

Artigo recebido em: 17/08/2015

Revisado pelos autores em: 28/03/2016

Aceito para publicação em: 30/03/2016 